\title{
INTERAÇÕES ESPACIAIS PROMOVIDAS PELOS CENTROS ESPÍRITAS MAIS PROPALADOS EM GOIÁS
}

\author{
SPATIAL INTERACTIONS PROMOTED BY THE MOST WELL KNOWN \\ SPIRITUAL CENTERS IN THE STATE OF GOIÁS
}

\section{INTERACCIONES ESPACIALES PROMOVIDAS POR LOS CENTROS ESPÍRITAS MÁS PROPALADOS EN GOIÁS}

\author{
Tito Oliveira Coelho \\ Doutorando em Geografia pelo IESA/UFG \\ E-mail: titocoelho2000@yahoo.com.br
}

\begin{abstract}
Resumo
Neste trabalho discorremos sobre a interação espacial dos centros espíritas de Abadiânia, Deuslândia, Goiatuba, Palmelo e Terezópolis com outros centros de cidades do território nacional e internacional. Analisamos as interações espaciais segundo a teoria dos fixos e fluxos, do movimento de 'pessoas' e 'coisas' que se relacionam mediante a busca de recursos para a cura física e extrafísica nos centros espíritas mais difundidos do Estado de Goiás. Com esta pesquisa não pretendemos mostrar os dogmas e as práticas da religião espírita, mas discutir o deslocamento e a circulação de pessoas, bem como o curso de medicamentos, o intercâmbio de ideias e fluídos no espaço geográfico humano.
\end{abstract}

Palavras-chave: Interação espacial. Centros espíritas.

\begin{abstract}
In this work, we talk about the spatial interaction of the spiritual centers of Abadiania, Deuslândia, Goiatuba, Palmelo Terezópolis and with other cities nationally and internationally. We analyze the spatial interactions, according to the theory of fixed and flows, the movement of 'people' and 'things' that are related by seeking resources for physical healing and spiritual centers in extraphysical most widespread of the State of Goiás With this research, not intend to show the tenets and practices of the spiritualist religion, but discuss the displacement and movement of people, as well as the course of medication, the exchange of ideas and fluids in space human geographic.
\end{abstract}

Key words: Spatial interactions. Spiritual centers.

\section{Resumen}

En este trabajo se habla de la interacción espacial de los centros espirituales de Abadiânia, Deuslândia, Goiatuba, Palmelo y Terezópolis con otras ciudades a nivel nacional e internacional. Se analizan las interacciones espaciales de acuerdo con la teoría de los fijos y los flujos, el movimiento de 'pueblo' y 'cosas' que están 
relacionados con la búsqueda de recursos para la curación física y espiritual en los centros espirituales más extendidos del Estado de Goiás. Con esta investigación no se pretende mostrar los principios y las prácticas de la religión espiritualista, sino discutir el desplazamiento y el movimiento de personas, así como el curso de la medicación, el intercambio de ideas y fluidos en el espacio geográfico humano.

Palabras-llaves: Interacción espacial. Centros espirituales.

\section{Introdução}

Neste trabalho se busca discutir a interação espacial promovida pelos centros espíritas mais difundidos no Estado de Goiás, região centro-oeste do Brasil, tendo as pessoas que procuram esses movimentos a finalidade de buscar recursos para a cura física e extrafísica "no" ser humano, por meio dos passes, de tratamentos fitoterápicos e de outras formas de influência mútua.

Apresenta-se, aqui, "Seu T.”, um estudioso e palestrante de temas cardecistas em Deuslândia, que explicou o termo "do": significa o "ser humano foi criado assim"; e "no" quer dizer: "foi criado com perfeição e o livre arbítrio o levou à imperfeição; na obra de Deus, não existe nada errado, nenhum mal...”. Por isso, destaca-se a expressão "no" no primeiro parágrafo deste artigo e nas notas iniciais.

Esta pesquisa está inserida na linha de Geografia Humana e as cidades que fizeram parte deste estudo foram: Abadiânia, Deuslândia, Goiatuba, Palmelo e Terezópolis, todas no Estado de Goiás. Portanto, o objetivo geral, aqui, é demonstrar a transferência de pessoas e de "coisas" de um ponto de origem (cidade, estado, país) a um destino (centros espíritas em Goiás), que representam os fixos interligados por fluxos em interação espacial, ou seja, mostrar como "fixos e fluxos interagem e se alteram mutuamente" (SANTOS, 1996a, p. 77-78).

Já os objetivos específicos são: i) discutir o conceito de migração, movimento, deslocamento e mobilização de pessoas; ii) apresentar o conjunto de centros espíritas que atendem a pessoas com problemas emocionais, mentais, espirituais e físicos (doenças) como forma alternativa aos males; iii) iniciar um discurso geográfico à respeito das interações espaciais, considerando-se a transferência de pessoas de uma área para outra, ou melhor, a demanda em direção à oferta de serviços espirituais. 
Quanto à metodologia, desenvolve-se, neste trabalho, uma pesquisa do tipo bibliográfica e de campo na área da Geografia Humana. Considera-se o mesmo como uma pesquisa bibliográfica tendo em vista a sua realização a partir do registro disponível, utilizando trabalhos concluídos, por meio de documentos arquivados, livros, artigos, monografias, teses, entre outros meios. Optou-se por este tipo de pesquisa porque "utiliza-se de dados ou categorias teóricas já trabalhados por outros pesquisadores e devidamente registrados" (SEVERINO, 2007, p. 122). Ou seja, é um tipo de pesquisa que recorre aos textos disponíveis, tornando-se referência e fonte do assunto a ser pesquisado. Ainda, foi trabalhada a pesquisa de campo, já que se pesquisou, in loco, a realidade geográfica goiana durante os rituais nos centros espíritas.

Para obter os dados foi realizada uma observação participativa em Abadiânia, no período de 2008 a 2009, e em Terezópolis (2009); observação participativa e entrevistas em Deuslândia (2009/2010); observação dos trabalhos no centro de Palmelo (2010); e, finalmente, entrevistas com servidores do centro de Goiatuba (2010).

O presente trabalho se justifica por haver poucos estudos no tocante ao movimento de pessoas em direção aos centros espíritas, já que alguns interessados nessa área se deparam, às vezes, com certas restrições e com receio do desconhecido. No entanto, percebe-se que este assunto é relevante à Geografia da Religião, às Ciências da Religião, à História da Religião, à Teologia, entre outras disciplinas. Então, para dar rigor científico ao trabalho, se analisa o tema sob a ótica das interações espaciais, visando alcançar o movimento, o deslocamento e a mobilização de pessoas e coisas no espaço. Sendo assim, é necessário explicar os conceitos que norteiam a investigação, a análise e a estrutura deste trabalho, que foi organizado em quatro tópicos, propondo discutir assuntos relevantes ao entendimento do assunto em pauta: i) interações espaciais como método de análise geográfica; ii) movimento e circulação de pessoas do território nacional e internacional em interação espacial com Abadiânia; iii) interações espaciais de Deuslândia com outras localidades; e iv) centro espírita em Goiatuba e o fluxo de pessoas e medicamentos.

Nas Considerações finais foi elaborado um breve diagnóstico do presente, tentando colaborar com interessados que estejam buscando uma (re)leitura dos estudos sobre o tema aqui proposto. 


\section{Interações espaciais como método de análise geográfica}

Ao tratar da interação entre lugares, Santos (1996a, 1996b) constatou que os espaços estão em interação a partir da teoria dos fixos e fluxos. Os fixos são os instrumentos de trabalho, as forças produtivas e a massa dos homens; os fluxos o movimento e a circulação que explicam os fenômenos da distribuição e do consumo: "fixos e fluxos interagem e se alteram mutuamente" (SANTOS, 1996a, p. 77-78). Em outra obra, ele salienta que fixos e fluxos interagem e expressam a realidade geográfica atual: "fixos e fluxos juntos, interagindo expressam a realidade geográfica e é desse modo que conjuntamente aparecem como um objeto possível para a geografia" (SANTOS, 1996b, p. 50). Nos tempos antigos também foi assim, mas os fluxos eram mais naturais e menos fixos ao solo, menos diversos, amplos, numerosos e mais lentos. Atualmente "tudo voa" (SANTOS, 1996b, p. 262), considerando-se a comunicação pela $\mathrm{TV}$, internet, rádio, revistas, jornais escritos e o boca a boca.

As interações espaciais são tidas, aqui, como fenômenos que se materializam mediante fluxos entre zonas: deslocamentos de pessoas, mercadorias, jornais, ligações telefônicas, transmissão de informações e realização de negócios (ULYSSÉA \& KÜHLKAMP, 2002) e, no caso deste estudo, deslocamento de pessoas de um lugar para outro. Em termos conceituais, o deslocamento de pessoas ocasiona interações espaciais entre os mais variados lugares e os centros espíritas estudados, quer dizer, conexões horizontais entre lugares a partir de um movimento físico de pessoas (ULLMAN, 1974).

Ao analisar os deslocamentos, Corrêa (1997, p. 279) disse que "as interações espaciais constituem um amplo e complexo conjunto de deslocamentos de pessoas, mercadorias, capital e informação sobre o espaço geográfico", podendo apresentar intensidades variadas, conforme a frequência, a distância e a direção. Ademais, podem caracterizar-se por distintos propósitos e ocorrerem através de meios e velocidades diferentes. Corrêa (1997, p. 279) ressalta que "as migrações em suas diversas formas", sejam elas definitivas, sazonais e pendulares, incluindo trocas entre países, circulação de mercadorias entre fábricas e lojas, deslocamento de consumidores, visitas diversas; idas ao culto, à praia, ao cinema, o fluir de informações aos consumidores e outros implicam em interação espacial, envolvendo a todos. Desse modo, o espaço está em interação 


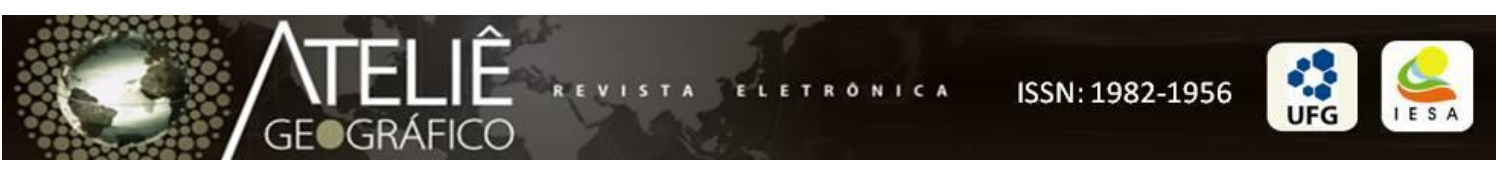

através dos fixos e fluxos, da transferência, da migração, do movimento, do deslocamento, da mobilidade, da origem e do destino de pessoas, coisas, informação, conhecimento e, neste estudo, da espiritualidade em interação com os 'encarnados'.

\section{Movimento e circulação de pessoas do território nacional e internacional em interação espacial com Abadiânia-GO}

Abadiânia (parte nova) é conhecida por vários países pelos tratamentos espirituais realizados entre as quartas-feiras e as sextas-feiras, por meio do médium "J. D.” e sua corrente de voluntários. É uma cidade do entorno de Brasília-DF que se limita com os municípios de Corumbá de Goiás, Alexânia, Silvânia, Anápolis e Pirinópolis, sendo um município de grande importância histórica para o país. Abadiânia divide-se em Velha e Nova, sendo o espaço original construído em torno de uma "casa de oração" bem simples, o qual se tornou atrativo festivo no dia de Nossa Senhora da Abadia. Atualmente, o sítio urbano original é um espaço pacato, com movimentações esporádicas, e o espaço mais recente, construído às margens da $\mathrm{BR}$ 060, a $18 \mathrm{~km}$ do sítio de origem, possui intenso movimento de pessoas em busca de cura espiritual.

Na parte nova da cidade está a "Casa de Dom Inácio", centro espírita cardecista onde "J. D." pratica cirurgias de efeito físico (por fluídos espirituais, banhos de cristais, banhos de cachoeira) e receita medicamentos fluidificados. Ao analisar a dimensão do reconhecimento de "J. D.”, Póvoa (2003, p. 68) ressaltou que "a fama de... [“J. D.”] ultrapassou as fronteiras do Brasil", devido à realização de trabalhos em seis países no exterior, pela divulgação na TV e por suas cirurgias "visíveis e invisíveis", cujas curas foram "comprovadas por vários cientistas de renome internacional". Isso provocou intenso deslocamento de estrangeiros rumo à Abadiânia Nova, ou seja, uma interação espacial internacional complementando a nacional por meio da procura de recursos para curas. Segundo Garcia (2006, p. 60), "pode-se dizer que são pessoas de todo o Brasil e de diversos países do mundo" que participam livremente do que quiser durante os rituais de cura. A casa conta com intérpretes para diversas línguas (a maioria inglês), cerca de 50 (cinquenta) guias para explicar o necessário, secretária, lugar de informações, traduções, entre outros serviços (figura 01). 


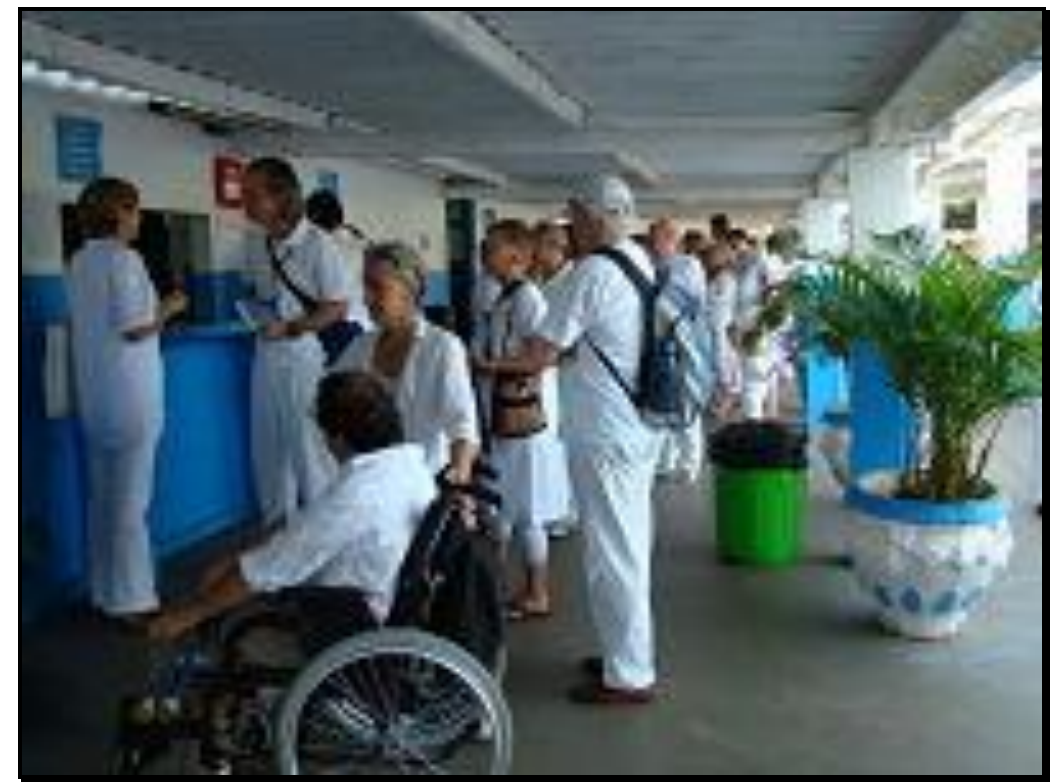

Figura 1: Fluxo de estrangeiros à procura de intérprete - Abadiânia-GO. Foto: Coelho (2009).

O médium “J. D." incorpora vários espíritos durante os trabalhos, sendo ajudado por grande corrente mediúnica que se concentra no interior da Casa. Ao analisar as entidades, Garcia (2006, p. 23) disse que “são muitas as 'entidades' que usam o "aparelho"' e que são identificadas por frequentadores da casa. São mais de 30 (trinta) entidades que "trabalham" com "J. D.", mas "as que estão quase que diariamente atendendo o povo, através dele" (PÓVOA, 2003, p. 50) são cinco principais: "Rei Salomão, D. Inácio de Loyola, Dr. Osvaldo Cruz, Dr. Augusto de Almeida e Dr. José Valdivino". Isso pode ser visto como uma modalidade de interação espacial também, pois movimenta e mobiliza seres 'desencarnados' e 'encarnados', sendo uns para dar e outros para receber curas espirituais.

O atendimento de "J. D." não onera os pacientes, porém, se receita uma fórmula de 04 (quatro) frascos (em média), contendo 45 (quarenta e cinco) cápsulas cada um, de passiflora (pó de maracujá) fluidificada, que custa $\mathrm{R} \$ 10,00$ (dez reais) cada, para alguns "pacientes". Os medicamentos são comercializados mediante receita expedida pelas entidades incorporadas em "J. D.", sendo "vendidas para as pessoas que podem pagar e dadas gratuitamente a quem não pode pagar" (GARCIA, 2006, p. 76). Diz-se que a entidade sabe quem pode ou não pagar e imprime um sinal na receita para que o funcionário não cobre pelos frascos. A venda de remédios gera lucros que são revertidos no preparo da sopa que faz parte do tratamento das pessoas, juntamente com os valores 
da venda de livros, cristais, terços e outros, na livraria, somados às bebidas e alimentos na lanchonete. Além disso, "também o médium J..., quando necessário, arca com as despesas". As viagens e as hospedagens na cidade são muito onerosas e "as dificuldades socioeconômicas afetam o fluxo de pessoas que procuram a Casa de Dom Inácio" (GARCIA, 2006, p. 63) tanto para brasileiros como para estrangeiros. A alternativa é mostrar fotos ou roupas de pacientes, levadas pelos guias ou parentes para o atendimento na Casa, pois a entidade as reconhece e manda o medicamento ou o fluído necessário para a cura.

Ao quantificar os dados dos motivos do fluxo de pessoas que procuram a Casa de Dom Inácio, Garcia (2006, p. 620) constatou que estes são por: tratamento de saúde, 75,6\%; passe, 18,8\%; curiosidade, 4\%; outros, 1,6\%. Quanto ao tempo de frequência, 60,2\% há menos de 1 ano; 18,6\% de 1 a 3 anos; 18,2\% de 4 a 6 anos; $3 \%$ acima de 7 anos. Isso mantém um fluxo de pessoas constante para trabalho e atendimento na instituição (figura 2) e, obviamente, para consumo na cidade.

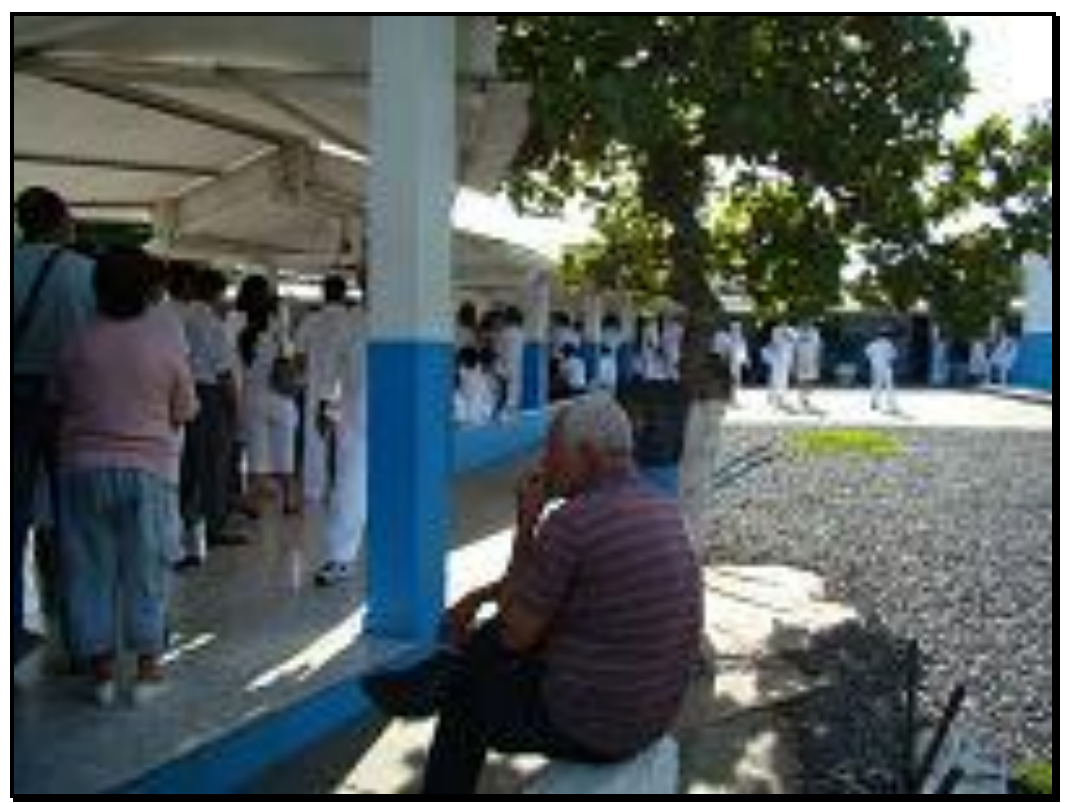

Figura 2: Pessoas em fila para serem atendidas por “J. D”. Abadiânia-GO. Foto: Coelho (2009).

Nos dias em que são realizados os trabalhos espirituais, a Casa de Dom Inácio se transforma em um destino ou fixo internacional com fluxo de pessoas da Europa, Austrália, Japão, Estados Unidos e outras nacionalidades, somados aos migrantes nacionais brasileiros. Assim, são distribuídos pequenos cartões, relativos a uma primeira 
ou segunda visita à instituição espírita, e, normalmente, os que se apresentam pela segunda vez recebem atendimento primeiro. Durante o deslocamento aos hotéis, pousadas, pensões, residências e cidades em direção ao centro espírita, a Casa de D. Inácio e as ruas próximas ficam repletas de pessoas com vestimentas brancas.

\section{Interações espaciais de Deuslândia com outras localidades}

Deuslândia (GO) é um povoado no entorno de Goiânia que sedia o "Centro Espírita Eurípedes Barsanulfo", às margens da Rodovia GO-222, a 50 km da capital, onde o médium "G." atende, por meio de psicofonia, às terças-feiras e aos sábados. O lugarejo é distrito de Brazabrantes (GO) e se interliga à Goiânia pelo Campus II da UFG, em direção à Nova Veneza; por Nerópolis, entrando, à esquerda ao lado do primeiro posto, depois de entrar na cidade no sentido Sul/Norte, ou seja, toma-se a direção Leste/Oeste. Outros acessos podem ser por Brazabrantes e Inhumas, para quem sai pela GO-070, que liga Goiânia à Goiás Velho, antiga capital do Estado de Goiás.

Outrora o centro espírita era na beira da rodovia, em uma instalação menor, mas o médium "G." "recebeu” orientações para construir outras instalações. A nova sede do centro, em Deuslândia, tem a forma de pirâmide e capacidade para 600 (seiscentas) pessoas sentadas no interior do salão (figura 3). Havia, portanto, a necessidade de uma sede maior para acolher pessoas de todo país. "Seu T." (palestrante há mais de 30 anos em Deuslândia) contou que: "na beira da estrada é movimentado e alguém podia se machucar". Assim, longe da estrada, haveria mais segurança e silêncio para o bom procedimento dos trabalhos. O espaço interno conta com consultórios clínico, odontológico, psiquiátrico e espiritual; no externo ficam a cozinha e o refeitório, a casa de apoio para eventuais hospedagens e um campo de futebol que atende as atividades educativa e recreativa para pessoas que procuram a instituição. 


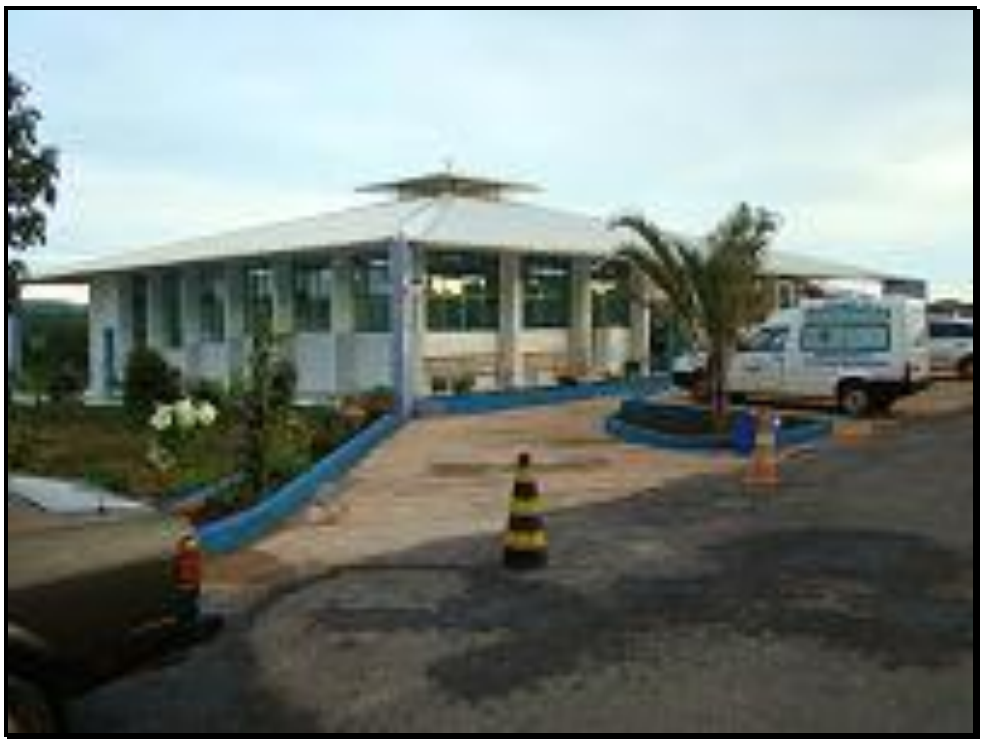

Figura 3: Nova sede do centro espírita de Deuslândia (GO). Foto: Coelho (2009).

No antigo lugar havia muitos curiosos que, conforme "Seu T." narrou, exclamando: "com a intenção de frequentar, não!!! Com a intenção de experimentar... essa situação... a pessoa fica sabendo... extraordinário... chega lá e não tem capacidade de captação e querer permanecimento, porque não dá para ver das primeiras vezes que vai lá”. Nesse sentido, as hierofanias ${ }^{1}$ influenciam no movimento de retorno ao lugar, pois o extrafísico causa curiosidade e, por essa razão, desperta a vontade de experienciação. Observe, na figura 4, o antigo lugar, mostrando uma pousada na frente e, em seguida, o 'velho' espaço do centro e seu estacionamento.

\footnotetext{
${ }^{1}$ Cabe destacar o conceito de hierofania (algo sagrado que se deixa mostrar em meio sacroprofano), resgatado por Rosendahl (1996, p. 27) como elemento espacial e fato geográfico concreto que ocorre no espaço.
} 


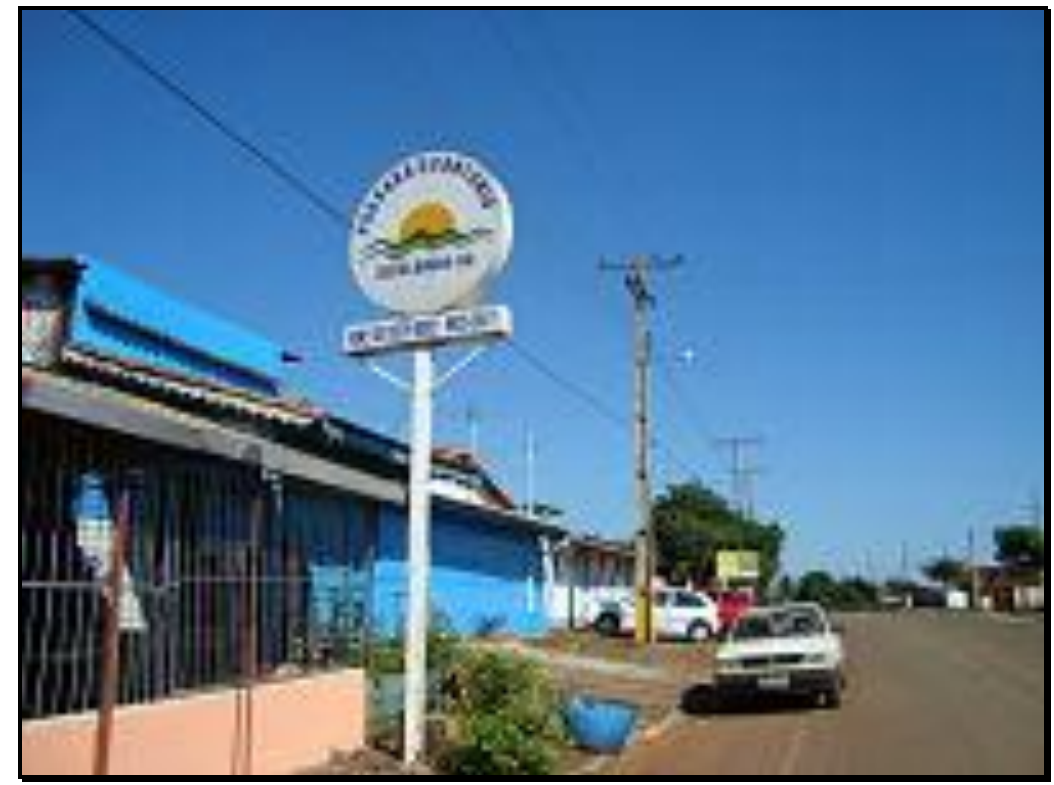

Figura 4: Pousada e antiga sede do centro espírita de Deuslândia. Foto: Coelho (2010).

Na nova sede do centro o fluxo de pessoas oscila de 25 (vinte e cinco) a 100 (cem) 'pacientes' (figura 5), mas "Seu T." argumenta que "quando era na beira da rodovia atendia de 500 (quinhentas) a 600 (seiscentas) pessoas por reunião... começava de manhãzinha e terminava entre 17 e 18 horas". Provavelmente o fluxo influenciou nas dimensões da nova instalação.

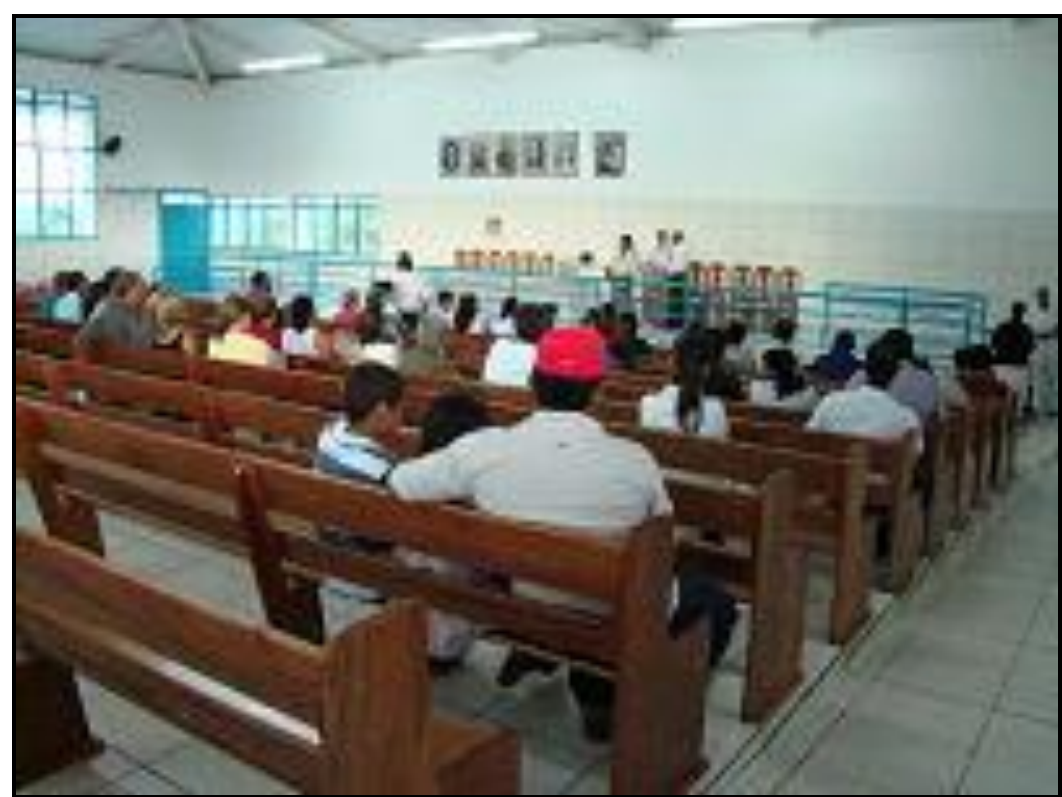

Figura 5: Início dos trabalhos no interior do centro espírita - Deuslândia. Foto: Coelho (2010). 
"Seu T." informou que o fluxo de pessoas que se desloca para o centro de Deuslândia "é mais de Brasília, Rio Verde (GO), Jataí (GO), Porto Velho", mas observa-se considerável movimento de pessoas de Goiânia e seu entorno, sendo diferente de Abadiânia, em que há mais interação com o estrangeiro. Segundo "Seu T.", os estrangeiros que frequentam o centro são de "Portugal, Bolívia, Sibéria, alguns do Japão e quase insignificante número do Paraguai, Argentina". Geralmente, o público procura Deuslândia para obter contato com parentes 'desencarnados', curas e outros recursos. A cidade, mais parecida com uma vila, hoje tem, basicamente, duas pousadas simples, porém, de certa forma, suficientes para acolher os pacientes que procuram pernoite.

A necessidade de pernoitar no lugar, de segunda para terça-feira e de sexta-feira para sábado, justifica-se pelo fato de os trabalhos começarem por volta das $6 \mathrm{~h}$, sendo necessário adquirir senhas para o atendimento no gabinete do médium. Mesmo saindo de Goiânia às 6h nos dias de mais movimento, provavelmente o paciente pegará a senha de número 70 em diante e terá que ficar o dia todo aguardando atendimento. O fluxo de pessoas varia muito em Deuslândia (figura 6).

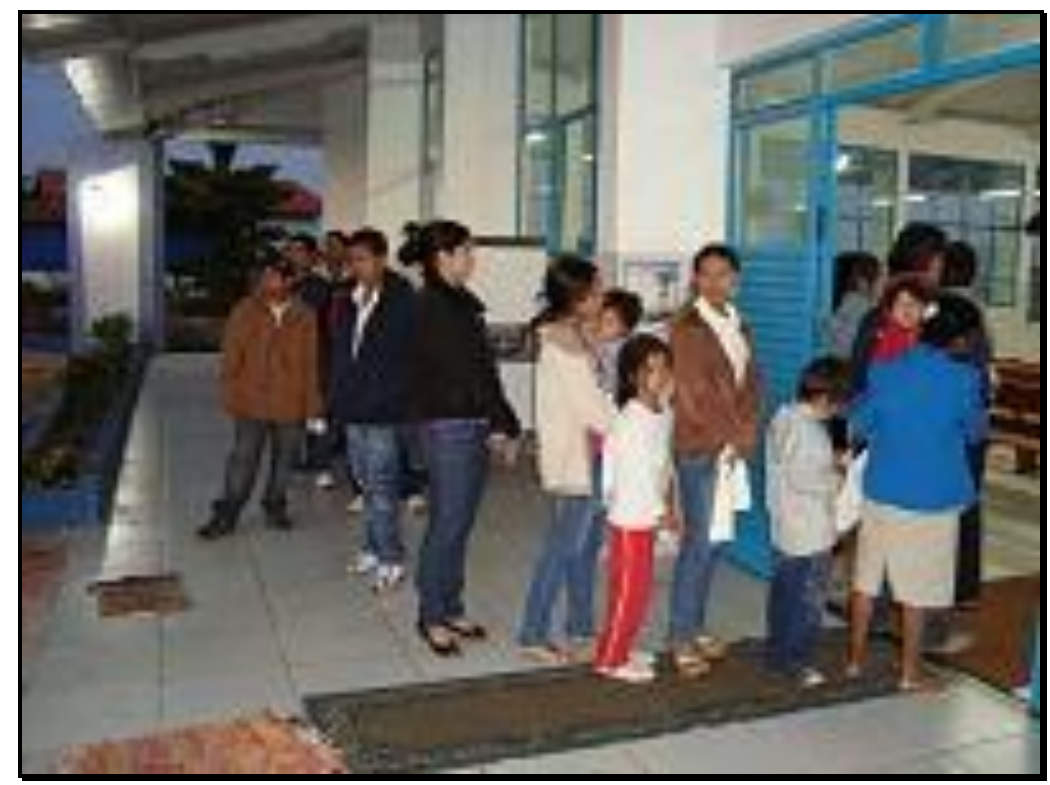

Figura 6. Fila para trocar senha e registrar-se no livro do dia - Deuslândia. Foto: Coelho (2010).

O trabalho no centro espírita em Deuslândia é de segunda a quinta-feira e aos sábados. Nas segundas-feiras há reuniões públicas com palestras doutrinárias e passes 
de cura a partir das 20h; às terças-feiras acontecem os atendimentos fraternos (psicofonia); às quartas-feiras são realizados estudos sistematizados dos ensinamentos espíritas; às quintas-feiras há práticas mediúnicas; e aos sábados são os mesmos procedimentos das terças-feiras, com mensagens de espíritos desencarnados. Nos dias de terça-feira o médium e outros palestrantes discursam antes dos trabalhos. Quando o médium incorpora e passa a atender seus pacientes, os palestrantes se revezam em seus discursos-ensinamentos para que o público não se disperse e interfira nos trabalhos. As palestras também fazem parte dos trabalhos da casa e acredita-se que as entidades iniciam os trabalhos com os pacientes já durante o discurso realizado no centro. Segundo informações de "Seu T.", são "484 entidades que incorporam, mas não é todo dia esse número; é uma situação alternada, podendo vir egípcios, árabes... de todo país... da Terra, à medida que recebem permissão para vir". Os espíritos que vêm para “trabalhar" e são incorporados por "G." têm a capacidade de comunicar-se e perceber os que aparecem para passar mensagens para os parentes que ainda estão "vivos". "Seu T." explicou que os "entes são uma interação que ajudam, mesmo na condição de se comunicar... às vezes sim ou não... outros não têm permissão para se comunicar... então a psicofonia... através dela há muita orientação por conselho e indicação medicamentosa".

Quando um 'paciente' recebe uma comunicação o médium pega em sua mão e o conduz para o palco para dar testemunho da psicofonia. Em 2009, ao entrevistar a "paciente" "M." esta informou que entrou e deixou seu esposo no banco; logo o médium lhe disse: "alguém de sua família morreu matado"? Então "M." lhe respondeu, com dúvidas: "É... morreu". O médium replicou dizendo: "por acaso o nome dele começa com L"? Perplexa "M." disse: "O quê"? O médium disse: "Deixa eu ir buscar seu marido". Chegando ao banco que fica na porta da cabine mediúnica, pegou nas mãos do esposo de "M." e o levou juntamente com sua sobrinha. Chegando lá, o médium disse que o esposo havia recebido uma comunicação de "L.", assassinado a tiros há cerca de um ano, e indagou o porquê de o esposo não haver contado à família, fato confirmado pelo esposo. Logo, o médium perguntou quem estava brigado na família e "M." disse que era seu esposo. Em seguida o médium perguntou quem era "Seu J." e o esposo disse que era seu pai. Então o médium disse o apelido do irmão do esposo de “M.”: “E o 'N.'?”. Os três ficaram atônitos e o médium os conduziu para o 
palco para relatar a psicofonia ${ }^{2}$ recebida. É difícil conseguir informações de quem recebe uma comunicação quando apenas a pessoa sabe, pois ela fica emocionada (sai em lágrimas), dificultando a tomada de informações.

Um servidor da casa coordena o atendimento, chamando quatro pacientes de cada vez. Estes devem se deslocar dos bancos do salão e se sentar no banco de espera próximo à porta do gabinete mediúnico para receber atendimento. $\mathrm{O}$ funcionário mostra um cartão, contendo quatro números subsequentes, de acordo com a ordem de chegada, anota os números e os nomes das pessoas a serem atendidas. No intervalo da manhã os pacientes são convidados para se deslocarem ao refeitório para lanchar. Pela manhã, são servidos café, leite, chás e pão, sem ônus para os visitantes.

O almoço também é servido por volta do meio-dia, sem qualquer ônus para os visitantes e pacientes da casa. Enquanto o médium atende aos que chegaram mais cedo, os demais se deslocam do salão para o refeitório mambembe (figura 7), voltando, posteriormente, para aguardar atendimento. Ressalta-se que - segundo informações de "Seu T." - o médium tem duas horas de intervalo, mas nem sempre as utiliza. Sua comida é servida em uma sala separada, próxima à cabine mediúnica, onde se recompõe e repousa por algum tempo. Os alimentos são feitos com mantimentos doados por diversas pessoas, sejam visitantes, pacientes e/ou outros doadores.

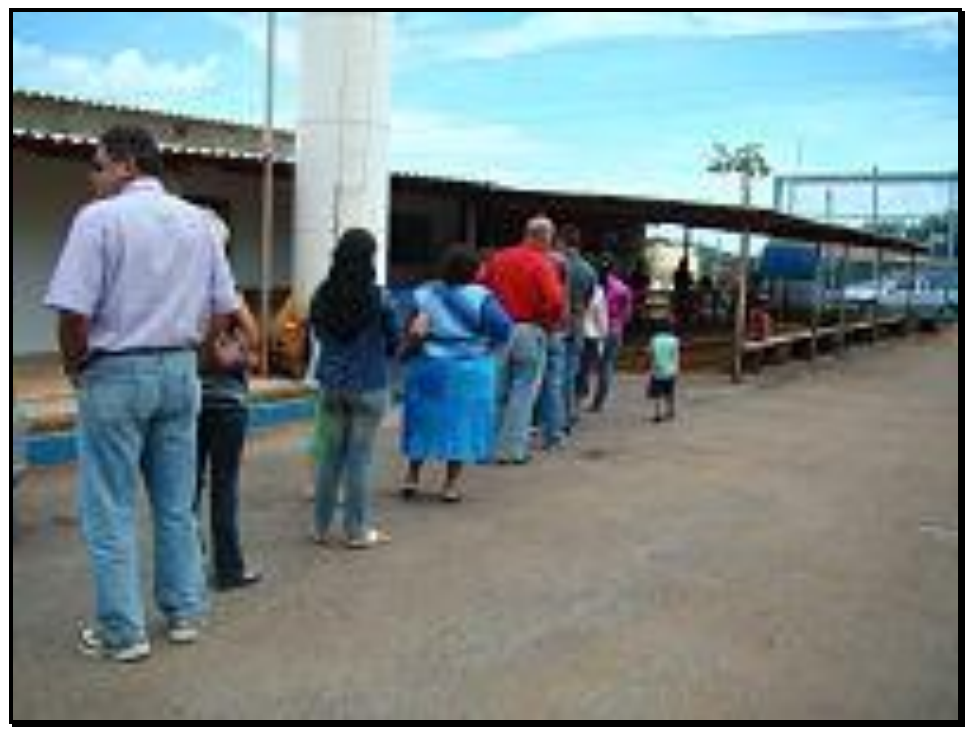

Figura 7: Fila para o almoço no refeitório do centro espírita - Deuslândia. Foto: Coelho (2010).

\footnotetext{
${ }^{2}$ Pisicofonia é relativo à alma e à voz, ou seja, é o fenômeno mediúnico no qual um espírito desencarnado se comunica por meio de um médium ou mediador, pessoa que estabelece o elo entre os homens e o mundo espiritual. Os contatos espirituais com os homens podem se dar por sonhos, visões conscientes estando acordado, psicografias, psicofonias, intuições e outros meios.
} 
No dia do levantamento preliminar desta parte do trabalho o almoço foi arroz, feijão, salada e carne bovina moída, acompanhado de um copo de suco. Tudo isso produz movimento, deslocamento e mobilização de pessoas, sendo exemplo de interações espaciais específicas em que o extraordinário, a surpresa, a curiosidade e o extrafísico são causas específicas em Deuslândia. Já na cidade de Goiatuba, a fitoterapia $^{3}$ é a causa específica de tal movimentação, cujo assunto é descrito no tópico a seguir.

\section{Centro Espírita em Goiatuba e o fluxo de pessoas e medicamentos}

Em Goiatuba (GO), localizada às margens da GO-320, a cerca de $10 \mathrm{~km}$ da BR 153, sentido Goiânia/Itumbiara, está o Grupo Espírita da Paz - o centro espírita da cidade - especializado em fitoterapia. São manipuladas muitas variedades de 'chás', através de fórmulas espirituais, uma interação dos cientistas do 'alto'(extrafísicos) com os da Terra (físicos). No início dos trabalhos, o orientador foi o médium Chico Xavier e, no ano de 1988, este emancipou os trabalhos, ou seja, estava seguro sobre o trabalho desenvolvido pelo grupo local. Veja o que disse o médium "D." a esse respeito: “convivemos muitos anos com nosso Chico Xavier, sempre levávamos as fórmulas e ele as completava, isso até 1988, quando ele disse que o barco correria por nossa conta, pois a espiritualidade maior confiava e fazia entregue em mãos do nosso serviço". De forma distinta dos centros de Abadiânia, Deuslândia, Palmelo e Terezópolis, a mediunidade no centro de Goiatuba se dá por intuição, como afirmou "D.": "nosso trabalho é todo por intuição".

Um dos principais atendimentos ocorre às sextas-feiras, com início às $7 \mathrm{~h}$. Segundo a secretária "C." "vem gente de tudo quanto é lugar" para ser atendido. O fluxo de pessoas é local, regional e nacional, atendendo a pessoas do Estado de Goiás (Cachoeira Dourada, Panamá, Buriti Alegre, Goiânia, Monte Alegre, Goianápolis), Tocantins (Palmas e outros), Minas (Uberaba, Uberlândia, Araguari), São Paulo e outros estados. Conforme informações de "D.", os pacientes são de Minas, de Goiás e do Norte, sem saber precisar de onde, pois não se preocupam com a procedência deles: 
"nossos pacientes, em sua maioria, são mineiros, goianos, mas temos recebido pessoas de diversos locais do Norte. A bem da verdade não perguntamos".

Como o atendimento é realizado pela manhã, as pessoas podem pernoitar na cidade, pois o "Senhor D." afirmou que "temos um hotel que cobra quase nada das pessoas que vêm tratar". Toda aglomeração de pessoas atrai o mercado e seus mercadores, e, em Goiatuba, foram tomadas providências para evitar a exploração dos pacientes. "D." disse que em "certa feita, inúmeras pessoas do lado de fora, já instalados carros, barracas, etc. e alguém cobrando ingresso", aproveitando a oportunidade para comercializar o espaço; então, “imediatamente, buscamos recursos para multiplicar o número de farmácias em centros espíritas. Graças a Deus a romaria sumiu”. Nas sextasfeiras, o trabalho consiste em evangelho e atendimento a enfermos, quem necessitar pode ficar deitado nos leitos da enfermaria, recebendo atendimento espiritual. O número de pessoas atendidas por dia, segundo "D.", não é tão grande, uma vez que "dificilmente ultrapassa cem pessoas". Mesmo assim, tal fato não deixava de ser atrativo para certo fluxo de comerciantes e prestadores de serviços. $\mathrm{O}$ atendimento é realizado em pequeno salão no centro espírita de Goiatuba (figura 8).

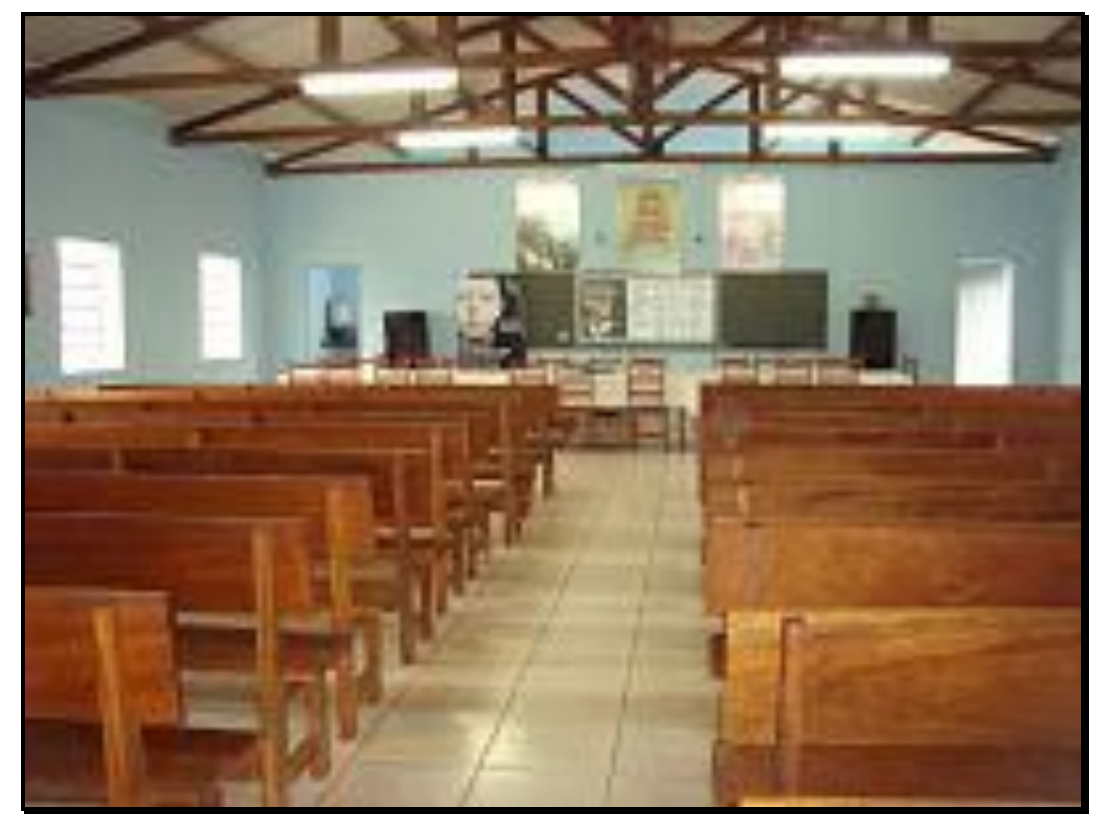

Figura 8: Interior do salão de atendimento do centro espírita de Goiatuba (GO). Foto: Coelho (2010).

\footnotetext{
${ }^{3}$ Fitoterapia é o tratamento com remédios manipulados com plantas; uso do princípio ativo dos vegetais para a prevenção e o tratamento de doenças.
} 
Os medicamentos são distribuídos de forma gratuita aos pacientes. A secretária "C." informou que "são inúmeras pessoas que vêm de longe e não podem ficar vindo aqui e "M." manda pelo Correio" os remédios. São, geralmente, pessoas de São Paulo, Goiânia e Aparecida de Goiânia, conforme informou durante entrevista. Isso gera intenso movimento de pessoas e coisas e, por conseguinte, interação espacial do citado centro espírita com várias cidades. Para 'controlar' o fluxo de pessoas à procura de cura na cidade e para evitar certos transtornos, tanto para migrantes-peregrinos quanto para o centro espírita e a cidade, foram criadas várias farmácias pelo país. Segundo informações de "C.", era necessário contribuir, de alguma forma, com os pacientes menos favorecidos: "a razão de ter criado as farmácias localizadas de Brasília a Cascavel no Paraná foi, exatamente, para os pobres não terem que se colocar na estrada". Nesse caso, se diminuiu a interação através do fluxo de pessoas, mas intensificou a de medicamentos e a transferência deles para outras cidades, proporcionando movimento, deslocamento e migração de menos pessoas, aumentando, assim, a transferência de medicamentos de uma cidade para outra. Por esse motivo, manteve-se a interação espacial, porém de forma diferente, isto é, favorecendo aos necessitados. Na figura 9, vê-se a quantidade de medicamentos 'descansando' nas prateleiras e os frascos à espera de envasamento.

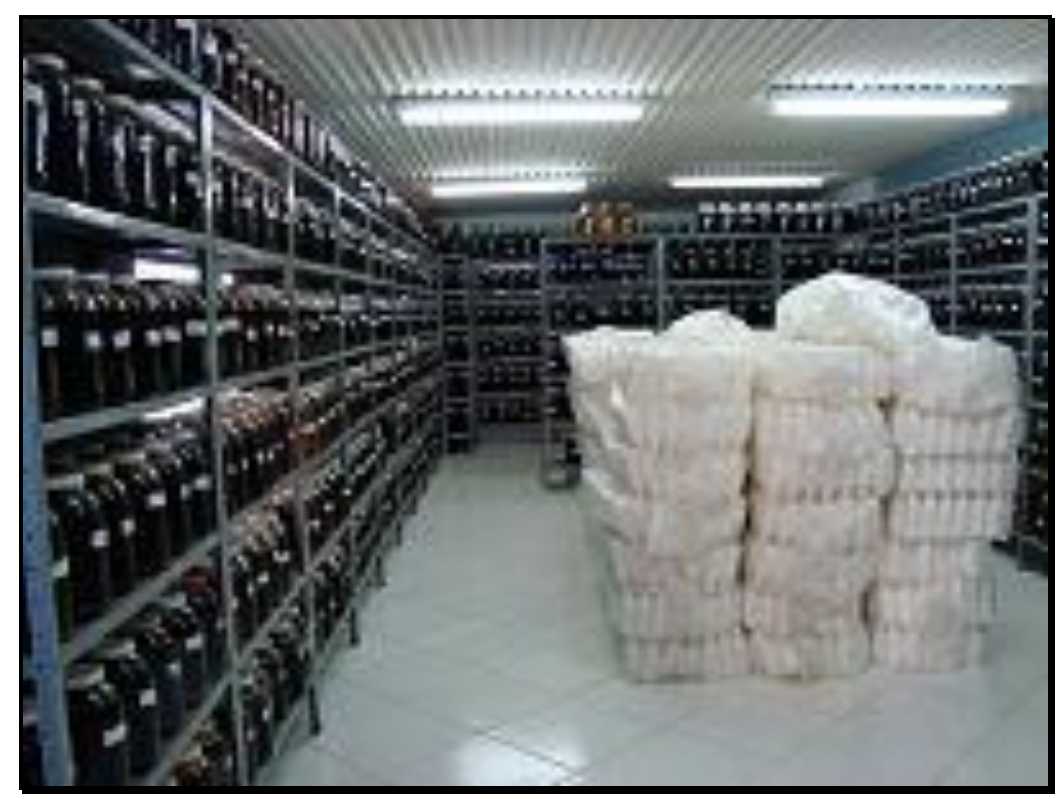

Figura 9: Medicamentos manipulados à espera de envasamento.

Foto: Coelho (2010). 
A instituição - segundo a secretária "C." - se interliga a mais de 70 (setenta) farmácias fora da cidade, sendo 10 (dez) postos de fabricação de pomadas. Ademais, "tem remédio para tudo que você imaginar, de labirintite para cima [...]" (Cf. http://www.paz.org.br/sitenovo/ index.php?page=fito). O médium "D." relatou que "atendemos mais de 1.000.000 pessoas/ano, gratuitamente, inclusive com franquia postal [...] hoje mantemos 71 (setenta e uma) farmácias e 10 (dez) postos de fabricação de pomadas". As cidades para onde os medicamentos se destinam são: no Estado de Goiás - Anápolis, Aparecida de Goiânia, Itumbiara, Morrinhos, Vicentinópolis, Paranaiguara, Jataí e outras; em Minas Gerais - Araxá, Uberaba, Uberlândia; em São Paulo - cidade de São Paulo, Mirassol, Catanduva, Campinas, Franca, Pindamanhagaba, Ribeirão Preto, Marilha, Moji Mirim, etc.; e em Mato Grosso do Sul - Campo Grande e outras. Podemos notar, na figura 10, a existência de grande quantidade de medicamentos prontos para distribuição no local e para envio.

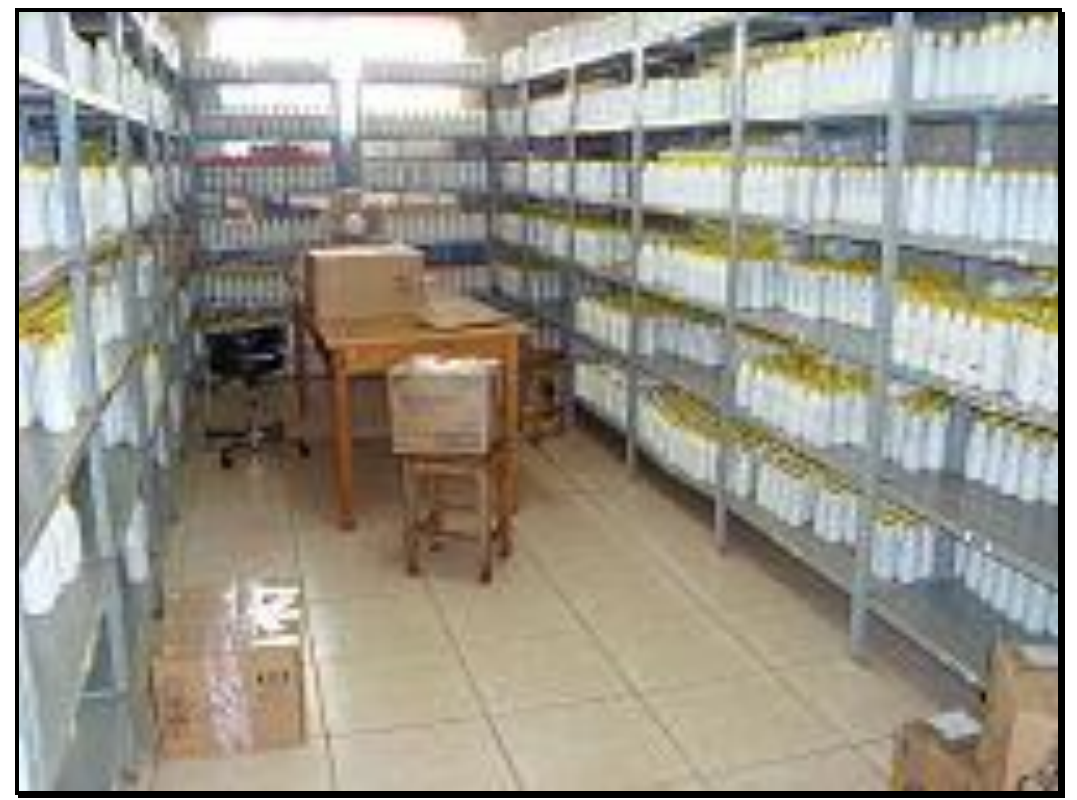

Figura 10: Medicamentos já envasados nas prateleiras. Foto: Coelho (2010).

O "Senhor D." afirmou que "nossos medicamentos cobrem o País e sendo enviado a diversos países”. Nesse caso, a rede geográfica é um elemento espacial muito importante para as interações dos mais diversos lugares com o centro espírita, uma vez que as localizações articuladas entre si por vias (fixos) e fluxos de pessoas, 
medicamentos e ideias permitem efetivamente a realização das interações espaciais (CORRÊA, 1997, p. 306).

O quadro de trabalho semanal proporciona intensa movimentação e mobilização de pessoas na cidade. Na segunda-feira, juntamente com trabalho de enfermaria e evangelização, realiza-se, em três salas, uma reunião aberta, a partir das 19h30. Nas terças-feiras, voluntários de Buriti Alegre e Itumbiara se deslocam para Goiatuba para prensar e envasar remédios e, ainda, servem sopa na unidade Chico Xavier às $13 \mathrm{~h}$ e há reuniões abertas nas unidades Chico Xavier e Jesus de Nazaré a partir das 19h30. Nas quartas-feiras há distribuição de medicamentos na unidade Chico Xavier mediante consulta. Às quintas-feiras é feita uma reunião aberta, na unidade Jesus de Nazaré, a partir das 19h30, com tratamento de enfermaria e evangelização em três salas; cerca de 50 (cinquenta) crianças de 0 (zero) a 14 (catorze) anos são atendidas. Como já comentamos, nas sextas-feiras são realizados evangelismo, atendimento ao público e envio de medicamentos para outras cidades. Nos sábados, há evangelização com distribuição de sopa a partir das $8 \mathrm{~h}$ e, às $10 \mathrm{~h}$, é coordenado o evangelismo. Nos domingos, quatro pessoas saem plantando sementes e seis pessoas as colhem com a finalidade de fazer a campanha do quilo. Outros trabalhos também são realizados: visita a presos, enfermos e atendimento volante de distribuição de remédios em cidades vizinhas e favelas.

Todo esse processo de atendimento espiritual, manipulação de medicamentos com plantas, evangelização e outros serviços demandam um quadro de funcionários. $\mathrm{O}$ centro espírita de Goiatuba possui 24 (vinte e quatro) funcionários remunerados, entre motorista, eletricistas, encanadores e os que trabalham na horta e na creche. $O$ vencimento é de acordo com a função. O custeio do centro é feito por doadores anônimos, que depositam dinheiro na conta bancária da instituição, e outras formas. $\mathrm{O}$ trabalho é complementado com serviço voluntário de várias pessoas, mostrando-se como lugar de intensa interação espacial com outros lugares. Existem outros centros espíritas com suas especificidades, as quais movimentam e promovem a circulação de pessoas.

Dois centros espíritas que chamam a atenção por provocarem a 'peregrinação' e o movimento de pessoas são os de Palmelo e Terezópolis. A primeira cidade fica a cerca de $140 \mathrm{~km}$ da capital, edificada nos arredores do "Centro Espírita Luz da Verdade" 
(figura 11), tendo sido fundada em 1929 e sendo considerada capital espírita do Brasil. Por causa do fluxo de pessoas foi construído um rancho para realizar as reuniões, o qual sofria com ameaças de incêndio constantemente. Lá, um dos médiuns de vidência e efeitos físicos mais conhecidos era o italiano "D.", que recebeu recomendação de Chico Xavier, em 1957, para, quando ouvisse o nome Palmelo, correr para o lugar. Depois de passar por vários lugares, chegou a essa cidade em 1958 e se apresentou para "J. C." e "Dona C.", que presidiam o centro. Tempos depois, "D." passou a vice-presidente, tornando-se presidente com o falecimento de "J. C.". Atualmente, as pessoas ainda procuram por psicografias nos dias de sexta-feira, a partir de meio-dia, em Palmelo (Cf. www.palmelo.com).

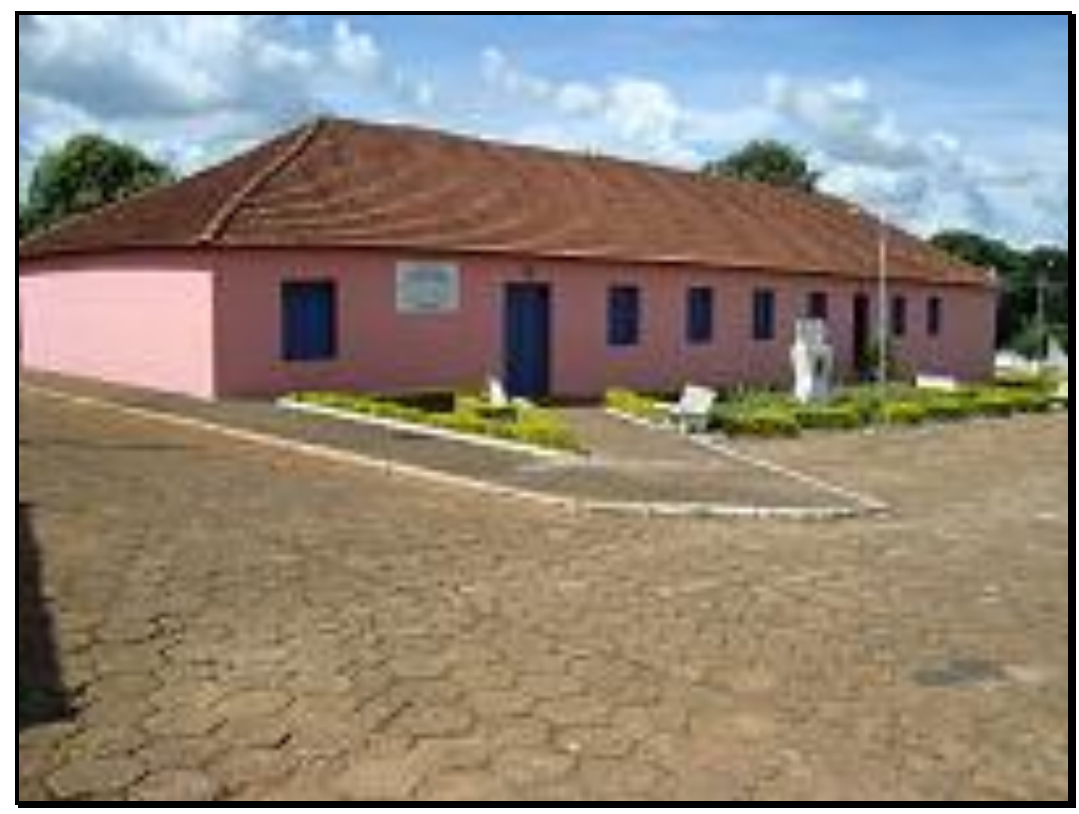

Figura 11: Centro Espírita Luz da Verdade, Palmelo (GO). Foto: Coelho (2010).

A segunda cidade fica a cerca de $30 \mathrm{~km}$ de Goiânia, em direção à Anápolis, onde está um dos templos do Vale do Amanhecer (figura 12), distinto do cardecismo, que trabalha na linha de caboclos e pretos velhos. Todos os dias há trabalhos, que começam por volta das 15h, cuja maior parte do público é de Goiânia e os médiuns, em sua maioria, de Anápolis. Nos dias de semana, o templo dispõe de cerca de 200 (duzentos) ou mais médiuns para atender a um fluxo de 50 (cinquenta) a 100 (cem) pessoas, segundo informações de um peregrinador por centros espíritas e uma diversidade de religiões, o "Senhor E.”. Conforme suas informações, há dias em que o fluxo entre 
médiuns e 'pacientes' pode chegar a aproximadamente 450 (quatrocentas e cinquenta) pessoas. Estes dois últimos lugares de culto também movimentam pessoas e ideias, formando uma rede de fixos interligada por fluxos em interação espacial.

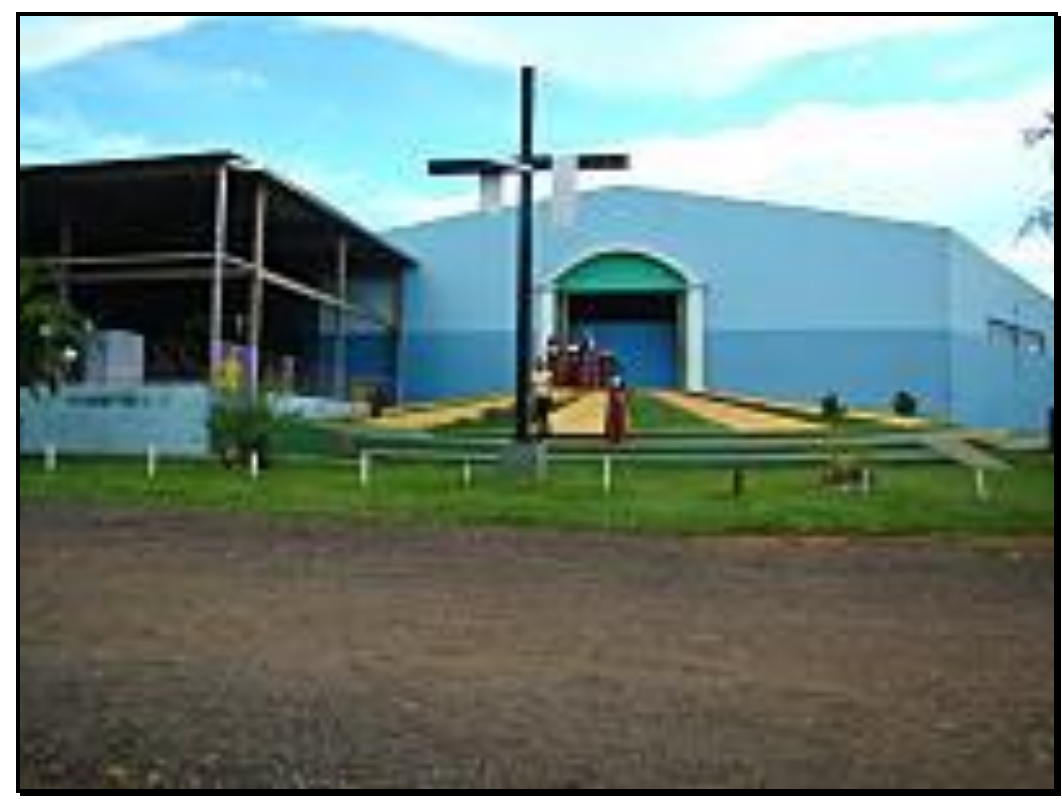

Figura 12: Templo do Vale do Amanhecer em Terezópolis (GO).

Fonte: Coelho (2009).

Ao comentar sobre a tecnosfera e a psicosfera, Santos (1996b, p. 203) ressalta que "a geografia dos fluxos depende, assim, da geografia dos fixos", prenunciando uma interação da noosfera com a biosfera. Para ele, o espaço geográfico se oferece "como abstração a ser interpretada" por um lado, mas, por outro, como "base a uma vida" cada vez mais "intelectualizada", por motivo da "tecnosfera dependente da ciência e da tecnologia" (SANTOS, 1996b, p. 204), criando paralelamente "uma psicosfera". Essa é a dimensão sutil das "ideias, crenças, paixões e lugar da produção de um sentido", fazendo parte também do meio ambiente, que pode ser percebido como invólucro da vida, "fornecendo regras à racionalidade ou estimulando o imaginário". Cada lugar possui tecnosfera e psicosfera em interação com uma sociedade mais ampla, que inclui um sistema de comunicação como elo articulador e mobilizador das ideias, ou seja, a movimentação do pensamento que antecede o de pessoas e coisas. Então, há uma tecnosfera em interação com a psicosfera por meio dos valores sociais, em que uma nebulosa dinâmica sustenta, conduz e antecede a concretização de uma técnica ou meio de cura, por exemplo. Enfim, "tecnosfera e psicosfera são redutíveis uma à outra" 
(SANTOS, 1996b, p. 204), condicionando novos comportamentos, novas racionalidades e até mesmo irracionalidades no espaço.

Ao comentar sobre essas ideias, Morin (2003, p. 44) disse que "todas as sociedades humanas engendram uma noosfera, esfera das coisas do espírito, saberes, crenças, mitos, lendas, ideias, onde os seres nascidos do espírito, gênios, deuses, ideiasforça ganham vida a partir da crença e da fé". Tal ideia adquire mais força-movimento ao se deparar com a hierofania, mensagens com a cura física ou espiritual. É na noosfera que se dá a condução (transferência) de mensagens do espírito livre para os encarcerados em um corpo físico. Ela é uma espécie de névoa (nebulosa em movimento) que separa os seres humanos do mundo espiritual, do qual a humanidade forma parte, que liga o homem ao 'desconhecido'. O que existe recobrindo a interação real entre os seres reais e os 'irreais' que se confundem? "Não se trata de um escapamento de fumaça, mas de um fervilhar de potências espirituais" (MORIN, 2003, p. 45). Na noosfera está contida a memória das sociedades, as quais são pouco percebidas; aqueles que as percebem exercem poder sobre os outros, uma vez que há uma autotranscendência proveniente da energia psíquica que pode captar desejos, fraquezas, medos, prazeres, angústias e outros. A interação entre noosfera e biosfera pode gerar mutualismo, mas também parasitismo e extorsão.

Ao indagar sobre o sentido da globalização atual que não é proveniente da criação de uma noosfera, Boff $(2003$, p. 57) certifica que a "seta do tempo e a linha da evolução vão no sentido de criar cada vez mais complexidades auto-organizadas, diversidades e inter-retrorrelacionamentos". Para o autor, a evolução também dá seus saltos, como é o caso da formação de um embrião ao produzir freneticamente uma rede de neurônios: suas conexões transcendem o corpo físico, atingindo a atmosfera familiar, comunitária, social e, logicamente, planetária, a qual chamou de 'pan-relacionalidade'. Tudo converge, concentra, sintetiza-se "e constitui uma unidade superior" (BOFF, 2003, p. 58). Com o complexo sistema comunicacional, interdependências por intermédio das interações espaciais, a unificação humana e o acelerado processo de globalização, será que não se estão criando as precondições para uma nova Geografia Humana?

Caminhamos hoje para um sistema nervoso complexo e planetário, ou seja, para um cérebro globalizado, uma vez que há grande acúmulo de cérebros humanos 
transcendendo energias. Não há, então, uma interação dos cérebros através do pensamento, do desprendimento de energia mediante a sofisticação dos saberes, experiências, desenvolvimento da percepção como partes do planeta que somos. E isso não cria a unificação da mente humana por meio das interações espaciais entre os lugares, ou melhor, uma noosfera? E o que dizer das "comunicações extra-sensoriais das mentes" (BOFF, 2003, p. 58) em sincronia? Com o processo evolutivo, surgirá uma nova humanidade que caminhará para uma grande convergência, baseada na reciprocidade (interação), que culminará numa "espécie de cérebro do planeta Terra" (BOFF, 2003, p. 60). A sintonia e a sincronia com todos os movimentos da e na terra proporcionará mais interação com ela e deixará de rivalizar com a mesma. Pesa sobre os seres humanos a escolha de fazer ou deixar de fazer, concorrendo "para a criação desta nova fase da humanidade" ou impedindo que ela ocorra. Que se diga de passagem: é uma grande discussão para os geógrafos pensarem a interação entre o espaço já percebido com o ainda não percebido.

\section{Considerações finais}

Cada cidade e centro espírita que buscamos abordar têm, geograficamente, uma especificidade no atendimento. Fica evidente que essa movimentação promove interação espacial a partir de uma rede de fixos interligados por fluxos. Nos nossos dias, consideramos a comunicação pela TV, internet, rádio e de boca-em-boca como meios de divulgação dos fixos que atraem determinados fluxos. Nossa intenção não foi a de divulgar a religião, mas sim mostrar o deslocamento de pessoas, medicamentos, transmissão de informações e realização de diferentes formas de prestação de trabalho espiritual, havendo deslocamento de pessoas de um lugar para outro. Dessa forma, podemos analisar as conexões horizontais entre os lugares por meio do intenso movimento físico de pessoas, dentro e fora do Brasil.

Podemos, destarte, dizer que os centros espíritas permitem as interações espaciais por proporcionar amplo e complexo conjunto de deslocamentos de pacientes e informação sobre o espaço geográfico nacional e internacional. Essas interações apresentam intensidades variadas, conforme a localização, a distância e a especificidade dos centros espíritas; caracterizando-se por distintos recursos para tratamentos e 
ocorrendo através de meios físicos e espirituais e diferentes dinâmicas. As migrações emergem entre países, entre Estados e cidades do país, envolvendo a circulação de medicamentos entre lugar de manipulação e rede de farmácias. Por isso, observam-se o deslocamento e o movimento de agentes e pacientes, as visitas aos centros por necessidade ou curiosidade; a ida ao evangelismo, fazendo fluir informações aos carentes, entre outros recursos. Logo, se conclui que esse processo implica e configura intensa interação espacial, interligando os mais diversos lugares e as várias pessoas com suas distintas identidades.

Além da visão pela ótica das interações espaciais, os centros espíritas, assim como as romarias, as folias, as congadas, o São João, o carnaval e outros folguedos, são campos de trabalho abertos às outras categorias de análise. Portanto, esses eventos podem ser vistos como paisagem em movimento, rede, território e territorialidade, lugar, percepção e outras análises a serem realizadas por estudiosos, no intuito de dar mais movimento e renovação à ciência geográfica. Outrossim, são fenômenos que “expressam a realidade geográfica atual, os quais, conjuntamente, aparecem como um objeto possível para a geografia" (SANTOS, 1996b, p. 50).

\section{Referências bibliográficas}

BOFF, Leonardo. Civilização planetária: desafios à sociedade e ao cristianismo. Rio de Janeiro: Sextante, 2003. 132 p.

CORRÊA, Roberto L. Interações espaciais. In: CASTRO, Iná E. de; GOMES, Paulo C. da C; CORRÊA, Roberto L. (Orgs.). Explorações Geográficas. Rio de Janeiro: Bertrand Brasil, 1997. p. 279-318.

GARCIA, Ismar E. Curas espirituais. Goiânia: AB, 2006. 216 p.

GRUPO ESPÍRITA DA PAZ. Disponível em:

<http://www.paz.org.br/sitenovo/index.php>. Acesso em: 07 out. 2010.

MORIN, Edgar. O método 5: a humanidade da humanidade. Porto Alegre: Sulina, 2003. $312 \mathrm{p}$.

PALMELO a Capital Espírita do Brasil. Disponível em: <www.palmelo.com>. Acesso em: 07 out. 2010.

PÓVOA, José L. C. João de Deus: fenômeno de Abadiânia. Anápolis: Múltipla Gráfica e Editora LTDA, 2003. 87 p. 
ROSENDAHL, Zeny. Espaço e religião: uma abordagem geográfica. Rio de Janeiro: EdUERJ, NEPEC, 1996. 89 p.

SANTOS, Milton. Metamorfoses do espaço habitado. São Paulo: Hucitec, 1996a. 124 p.

A natureza do espaço: técnica e tempo, razão e emoção. São Paulo: Hucitec, 1996b. 308 p.

SEVERINO, Antônio J. Metodologia do trabalho científico. São Paulo: Cortez, 2007.

ULLMAN, E. L. Geography as spatial interaction. In: ELIOT-HURST, M. E (Ed.). Transportation Geography: Comments and Readings. New York: McGraw-Hill, 1974. p. 27-40.

ULYSSÉA NETO, Ismael; KUHLKAMP, Nilo. O tratamento do espaço em modelos de interação Espacial: considerações sobre a determinação das oportunidades intervenientes. Congresso Brasileiro de Cadastro Técnico Multifinalitário/COBRAC 2002, UFSC, Florianópolis, 06-10 out. 2002. Disponível em: <http://geodesia.ufsc.br/Geodesia-online/arquivo/cobrac_2002/018.HTM>. Acesso em: 30 jan. 2007.

Recebido para publicação em outubro de 2010. Aprovado para publicação em fevereiro de 2012. 